\title{
Utilization of Postnatal Care Service in Indonesia and its Association with Women's Empowerment: An Analysis of 2017 Indonesian Demographic Health Survey Data
}

\author{
Susy K. Sebayang ${ }^{1,2}$ (D) Eka M. M. Has $^{3}$ (D) $\cdot$ Setho Hadisuyatmana ${ }^{(D)} \cdot$ Ferry Efendi $^{3,4}$ (D) Erni Astutik ${ }^{1,5}$ (D) \\ Heri Kuswanto ${ }^{6}$
}

Accepted: 24 November 2021 / Published online: 11 January 2022

(c) The Author(s), under exclusive licence to Springer Science+Business Media, LLC, part of Springer Nature 2021

\begin{abstract}
Objective The coverage of postnatal care (PNC) is among the lowest globally when compared with other maternal and child interventions. This study aims to assess PNC utilisation in Indonesia and its association with women's empowerment indicators to provide evidence for the need for policy change.

Methods Data from the 2017 Indonesian Demographic Health Surveys was analyzed for any use of PNC, early first PNC (within 2 days of birth) and PNC after discharge for newborns. Women's empowerment factors were calculated using a principal component analysis of 17 indicators. The association between women's empowerment factors and PNC was assessed using logistic regression adjusted for covariates and complex survey design.

Results The prevalence of any PNC by skilled professionals in Indonesia was high but PNC after discharge was very low. Labor-force participation and women's knowledge level were associated with any PNC, but the association between women's knowledge level and any PNC was modified by place of birth. Disagreement towards justification of wife beating and women's knowledge level were associated with early PNC but the association was modified by place of birth. Decision-making power was also associated with early PNC but modified by infant's gender. Disagreement towards justification of wife beating was negatively associated with PNC after discharge, but the association between decision-making power and PNC after discharge was modified by the infant's size at birth.

Conclusions for Practice PNC coverage after discharge in Indonesia needs improvement. Women's empowerment indicators need to be addressed in improving PNC coverage.
\end{abstract}

Keywords Newborn postnatal care $\cdot$ Female labor force participation - Decision making power · Domestic violence . Knowledge · Women's empowerment

Susy K. Sebayang

sksebayang@fkm.unair.ac.id

1 Research Group for Health and Well-Being of Women and Children, Universitas Airlangga, Surabaya, Indonesia

2 Department of Epidemiology, Biostatistics, Population Studies and Health Promotion, Faculty of Public Health, Universitas Airlangga, Banyuwangi Campus, Jl. Wijaya Kusuma No. 113, Banyuwangi, East Java 68425, Indonesia

3 Faculty of Nursing, Universitas Airlangga, Surabaya, Indonesia

4 Research Group of Community Health, Surabaya, Indonesia

5 Department of Epidemiology, Biostatistics, Population Studies and Health Promotion, Faculty of Public Health, Universitas Airlangga, Surabaya, Indonesia

6 Department of Statistics, Institut Teknologi Sepuluh Nopember (ITS), Kampus ITS Sukolilo, Surabaya, Indonesia

\section{Significance}

Despite its being one of the most effective interventions for achieving the required reduction of neonatal deaths by 2030 , the coverage of postnatal care (PNC) is among the lowest globally, when compared with other maternal and child interventions. Women's empowerment has been less studied in relation to PNC utilization. This paper analyzed the latest nationally representative data from Indonesia. We found that women's empowerment was associated with PNC utilization but the association varied by place of birth, infant's size and gender. This paper is thus important in providing information for policy change in neonatal health. 


\section{Introduction}

Sustainable development goals established targets for all countries to reduce neonatal mortality to a maximum of 12 per 1000 live births by 2030. In addition to facility birth, postnatal care (PNC) is one of the effective interventions that could help countries to achieve this target. Both skilled and unskilled PNC check-ups two hours to two days after delivery were associated with neonatal death reduction (Baqui et al., 2009; Singh et al., 2014). Infants who did not have PNC check-up had up to three times the odds of having neonatal complications at 6 weeks after birth (Kikuchi et al., 2018) and PNC is also linked to improvement in breastfeeding (Khan et al., 2017) and prevention of infection (Blencowe et al., 2011), which also leads to improved survival. Facility birth and PNC are estimated to be able to reduce by one third the neonatal deaths in India alone, amounting to 100,000 deaths avoided per year (Fadel et al., 2015).

However, of all the maternal and child interventions, global coverage of PNC is among the lowest and needs improvement (Sacks \& Langlois, 2016). It has the highest discontinuation rate of elements in the continuum of care (consisting of antenatal care at least four times, delivery by skilled birth attendant, and PNC at least once) for maternal and child health care (Kikuchi et al., 2018). By the end of the Millennium Development Goal in 2015 the global coverage of PNC for newborns was merely $28 \%$. In Ghana, more than $25 \%$ of infants were born requiring medical attention, but only $29.1 \%$ of them received PNC in the first two days, and $52.4 \%$ within the first 2 weeks of life (Okawa et al., 2015). The issue of low coverage also occurs in Indonesia. In 2012 only 46\% of Indonesian infants had PNC check-ups conducted by skilled health providers within two days of birth (Statistics Indonesia (Badan Pusat Statistik-BPS), National Population and Family Planning Board (BKKBN), Kementerian Keseha$\tan ($ Kemenkes-MOH), \& ICF International, 2013). This amounted to more than 2.5 million births not followed by PNC check-ups every year in this country alone. Therefore, evidence to support a policy of improving PNC in this country is urgently needed.

Many studies have assessed the factors associated with the use of PNC. Women's education level, facility birth, number of antenatal care visits, and socioeconomic status were among the most commonly known to be associated with PNC use (Fekadu et al., 2018; Khanal et al., 2014; Singh et al., 2012). In Pakistan, health care providers reported that $90 \%$ of women were not interested in PNC due to affordability, mobility and transportation problems, and lack of awareness (Sultana \& Shaikh, 2015).

However, women's empowerment factors, apart from their education level, are rarely assessed in relation to the utilisation of PNC. A study found a link between the utilisation of PNC and women's exposure to media (Bwalya et al., 2017), and between the utilization of PNC and having a steady employment (Abuka Abebo \& Jember Tesfaye, 2018). Men's engagement in maternal health services has also been reported to be associated with improved PNC (Mon et al., 2018; Sakeah et al., 2018). A complete assessment of the association between women's empowerment and PNC utilization has not been available. Indonesia is one of the largest countries with low early PNC coverage in 2012 (Statistics Indonesia (Badan Pusat Statistik-BPS), National Population and Family Planning Board (BKKBN), Kementerian Kesehatan (KemenkesMOH), \& ICF International, 2013). This study therefore assessed the current PNC utilisation in Indonesia and its association with women's empowerment indicators using recently available data.

\section{Materials and Methods}

\section{Data}

A de-identified dataset of singleton, non-caesarian last births in the 5 years prior to the survey, with complete information on covariates from the Indonesian Demographic Health Surveys (DHS) 2017 downloaded from www.dhsprogram.com, was analyzed. Indonesian DHS employs a complex sampling design with stratification by regions and urban/rural areas before selecting households randomly from randomly selected clusters in each stratum (the sampling method is described in country reports available at www.dhsprogram. com). All participants provided informed consent prior to interview. The institutionalized Review Board (IRB) in ICF, as the DHS survey implementing agency, and the IRB in host countries approved the survey protocols. No further consent was needed for this analysis.

\section{Key Variables and Measurements}

The use of PNC was assessed using two indicators: having any PNC within 28 days of birth by trained health professionals including paediatrician, obstetrician, general practitioner, midwife, or nurse; and having early first PNC, which was defined as having the first PNC by trained health professionals within two days of birth. For those who delivered in a health facility, we also assessed any PNC after discharge. Women's empowerment factors were calculated using principal component analysis of 17 indicators and this resulted in four components: women's labor force participation, their disagreement with justification for wife beating, their decision-making power in the household and their knowledge 
level. Labor force participation was indicated by six aspects that included work aspects, type of payments and earnings; women's disagreement with justification for wife beating was assessed for five scenarios (neglect children, go out without husband's permission, argue with husband, refuse sex, and burn food); decision-making power was assessed with whether woman was involved in four household decision making; while the women's knowledge was assessed using formal educational level and access to mass media (television, radio, newspaper). Tertiles of each of the components were then created to categorize each component into low, medium and high level. Details of the 17 indicators and the method are available from a published study (Sebayang et al., 2019).

As can be seen in the analytical framework available in Supplementary File 1, we adjusted for covariates known to be associated with the use of PNC including:

- Child's factors: gender, birth ranking and interval between birth [second or third child $>2$ years apart from the previous child, first birth, second or third child $\leq 2$ years apart, fourth or higher child $>2$ years apart, or fourth or higher child $\leq 2$ years apart (Titaley et al., 2008)] and reported child's size at birth (small, average, large).

- Maternal factors: mother's age (15-19 years, 20-24 years, 25-29 years, 30-34 years, 35-39 years, or $40+$ years), and pregnancy desire (wanted then, wanted later, or unwanted).

- Paternal factors: age difference between mother and father (mother older than father, or 0-4 years, 5-7 years, or $>7$ years younger), father's occupation (agricultural or non-agricultural) and father's education (did not complete primary education or no schooling, completed primary or had some secondary schooling, completed secondary school or had some higher education).

- Household factors: wealth quintiles (poorest, poorer, middle, richer, richest), number of household member $(<4$ vs $\geq 4)$, and number of children under five $(<2$ vs $\geq 2$ ).

- Geography factors: region (West or East Indonesia) and residence (urban or rural).

- Health care factors: number of antenatal care (ANC) visits attended $(<4$ or $\geq 4)$, time of first ANC visit ( $<4$ months or $\geq 4$ months), quality of ANC received, place of delivery (delivery in health facility vs non health facility), household distance from health facility (distance a big problem vs not) and possession of health insurance (having any health insurance vs not). ANC quality was calculated by adding the number of health services the woman received during her pregnancy including weight, height and blood pressure measurements, abdominal examination, urine and blood tests, tetanus injection, having received or bought iron supplements and having ANC consultations. The quality was then categorized into $\leq 5,6-7$ and $>7$ types of ANC services mothers received in their last pregnancy.

\section{Statistical Analysis}

Descriptive analysis was used to estimate the prevalence of PNC in Indonesia and a map of the differences between provinces was presented. We used logistic regression to determine associations between the four components of women's empowerment and the use of PNC (any PNC, early PNC and PNC after discharge) adjusted for covariates regardless of their significance. Interactions between women's empowerment components and covariates were tested and interaction with a p-value of $<0.01$ was considered significant. All analyses were conducted using STATA 15 using the svy commands to adjust for the complex sampling.

\section{Results}

After including the last births occurring in the five years prior to the survey but excluding twins, caesarean births, and missing covariates, 10,365 births were included in the analysis. The prevalence of PNC was $84.1 \% ; 78.5 \%$ had PNC within two days of delivery and only $32.6 \%$ of infants born in a health facility received any PNC after discharge (Table 1). Eastern Indonesia lagged behind in PNC utilization, and low PNC after discharge occurred in both eastern and western Indonesia (Fig. 1). Around $41 \%$ of the Indonesian provinces had a prevalence of $<80 \%$ of any PNC, $71 \%$ of the provinces had $\mathrm{a}<80 \%$ prevalence of early first PNC, and none of the provinces had a prevalence of PNC after discharge of $>80 \%$ (Fig. 2). Interestingly, the provinces that were among the best at any PNC and early first PNC such as Yogyakarta, Bali and Jakarta (Fig. 2a, b) lagged behind in having PNC after discharge (Fig. 2c). In Yogyakarta and Bali, for example, the prevalence of any PNC were 97.5\% and $96.6 \%$ respectively, but only $42.6 \%$ of infants born in a health facility in Yogyakarta, and $20.4 \%$ in Bali, had any PNC after discharge (Fig. 2).

Most of the infants in the dataset were the second or third child aged $>2$ years apart from the closest sibling (50.4\%) and of a wanted pregnancy (84.5\%). Most women attended four or more ANC appointments during pregnancy (93.3\%) and started ANC early (84.5\%), mostly receiving 6-7 types of ANC services (47.3\%). Most infants were born in a health facility (79\%). Most infants belonged to households that had 4 or more members $(86.3 \%)$, had health insurance (57\%) and lived not far from the health service (88.7\%). Infants of women who belonged to the richest group and infants born in a health facility had the highest prevalence of any PNC 
Table 1 Characteristics of samples (population size $\mathrm{N}=10,365$ )

\begin{tabular}{|c|c|c|c|c|c|}
\hline & $\mathrm{N}$ & $\%$ & $\%$ Any PNC & $\begin{array}{l}\% \text { PNC } 2 \text { days of } \\
\text { birth }\end{array}$ & $\begin{array}{l}\% \text { PNC after discharge } \\
\text { 'for those born in health } \\
\text { facility' }\end{array}$ \\
\hline Received any postnatal care (PNC) & 8721 & 84.1 & & & \\
\hline \multicolumn{6}{|l|}{ Postnatal care within two days after birth } \\
\hline None & 1166 & 11.2 & & & \\
\hline PNC the first 2 days after birth & 8132 & 78.5 & & & \\
\hline PNC more than 2 days after birth & 1067 & 10.3 & & & \\
\hline \multicolumn{6}{|l|}{ PNC after discharge } \\
\hline No & 5520 & 67.4 & & & \\
\hline Yes & 2672 & 32.6 & & & \\
\hline \multicolumn{6}{|l|}{ Child's gender } \\
\hline Female & 5062 & 48.8 & 84.6 & 78.7 & 31.9 \\
\hline Male & 5303 & 51.2 & 83.7 & 78.2 & 33.3 \\
\hline \multicolumn{6}{|l|}{ Birth ranking and interval } \\
\hline Second or third child, interval $>2$ years & 5225 & 50.4 & 85.7 & 80.8 & 33.7 \\
\hline First birth & 3426 & 33.1 & 85.4 & 78.5 & 33.4 \\
\hline Second or third child, interval $\leq 2$ years & 437 & 4.2 & 81.3 & 74.5 & 26.8 \\
\hline Fourth or higher child, interval $>2$ years & 1117 & 10.8 & 76.1 & 70.6 & 27.5 \\
\hline Fourth or higher child, interval $\leq 2$ years & 161 & 1.6 & 71.0 & 68.6 & 25.9 \\
\hline \multicolumn{6}{|l|}{ Women's perception of infant size at birth } \\
\hline Small & 1179 & 11.4 & 82.1 & 75.2 & 31.7 \\
\hline Average & 5915 & 57.1 & 84.6 & 78.6 & 32.9 \\
\hline Large & 3272 & 31.6 & 84.1 & 79.4 & 32.4 \\
\hline \multicolumn{6}{|l|}{ Women's age } \\
\hline $15-19$ & 241 & 2.3 & 77.3 & 70.6 & 29.7 \\
\hline $20-24$ & 1841 & 17.8 & 83.0 & 76.4 & 33.3 \\
\hline $25-29$ & 2729 & 26.3 & 84.2 & 78.8 & 31.5 \\
\hline $30-34$ & 2650 & 25.6 & 84.8 & 79.4 & 34.7 \\
\hline $35-39$ & 1960 & 18.9 & 85.8 & 79.8 & 31.9 \\
\hline $40+$ & 945 & 9.1 & 82.6 & 77.9 & 30.6 \\
\hline \multicolumn{6}{|l|}{ Was the pregnancy wanted } \\
\hline Wanted then & 8759 & 84.5 & 84.0 & 78.3 & 32.6 \\
\hline Wanted later & 833 & 8.0 & 85.0 & 79.1 & 35.4 \\
\hline Unwanted & 774 & 7.5 & 85.1 & 80.0 & 29.7 \\
\hline \multicolumn{6}{|l|}{ Age difference between women and husband } \\
\hline Women older than man & 1762 & 17.0 & 86.9 & 80.6 & 31.2 \\
\hline $0-4$ years & 4184 & 40.4 & 83.5 & 77.5 & 32.3 \\
\hline $5-7$ years & 2269 & 21.9 & 83.7 & 78.7 & 33.4 \\
\hline$>7$ years & 2151 & 20.7 & 83.6 & 78.3 & 33.6 \\
\hline \multicolumn{6}{|l|}{ Father's occupation } \\
\hline Agricultural & 5466 & 52.7 & 80.2 & 74.9 & 34.4 \\
\hline Non-Agricultural & 4899 & 47.3 & 88.5 & 82.4 & 31.0 \\
\hline \multicolumn{6}{|l|}{ Husband's educational attainment } \\
\hline Incomplete primary education/none & 791 & 7.6 & 70.9 & 66.6 & 34.9 \\
\hline Completed primary or some secondary & 5002 & 48.3 & 81.1 & 76.0 & 33.0 \\
\hline Completed secondary or higher & 4572 & 44.1 & 89.8 & 83.3 & 31.9 \\
\hline \multicolumn{6}{|l|}{ Wealth quintile } \\
\hline Poorest & 2112 & 20.4 & 68.9 & 64.5 & 29.7 \\
\hline Poorer & 2245 & 21.7 & 83.9 & 78.5 & 35.9 \\
\hline Middle & 2255 & 21.8 & 86.1 & 80.9 & 32.7 \\
\hline
\end{tabular}


Table 1 (continued)

\begin{tabular}{|c|c|c|c|c|c|}
\hline & $\mathrm{N}$ & $\%$ & $\%$ Any PNC & $\begin{array}{l}\% \text { PNC } 2 \text { days of } \\
\text { birth }\end{array}$ & $\begin{array}{l}\% \text { PNC after discharge } \\
\text { 'for those born in health } \\
\text { facility' }\end{array}$ \\
\hline Richer & 2067 & 19.9 & 90.0 & 82.9 & 33.6 \\
\hline Richest & 1685 & 16.3 & 93.8 & 87.2 & 30.1 \\
\hline \multicolumn{6}{|c|}{ Number of household members } \\
\hline Household $<4$ & 1417 & 13.7 & 83.2 & 75.6 & 32.6 \\
\hline Household $\geq 4$ & 8948 & 86.3 & 84.3 & 78.9 & 32.6 \\
\hline \multicolumn{6}{|c|}{ Number of children $<5$ in household } \\
\hline Less than 2 & 8246 & 79.6 & 84.9 & 79.1 & 33.5 \\
\hline 2 or more & 2119 & 20.4 & 81.1 & 76.1 & 29.0 \\
\hline \multicolumn{6}{|l|}{ Region } \\
\hline West & 8682 & 83.8 & 84.7 & 78.6 & 33.8 \\
\hline East & 1683 & 16.2 & 81.0 & 77.5 & 25.7 \\
\hline \multicolumn{6}{|l|}{ Residence } \\
\hline Urban & 4777 & 46.1 & 89.6 & 83.2 & 29.3 \\
\hline Rural & 5589 & 53.9 & 79.5 & 74.4 & 36.3 \\
\hline \multicolumn{6}{|c|}{ Number of antenatal care (ANC) visits } \\
\hline Less than 4 & 693 & 6.7 & 63.7 & 58.8 & 25.0 \\
\hline 4 or more & 9672 & 93.3 & 85.6 & 79.9 & 33.0 \\
\hline \multicolumn{6}{|c|}{ Timing of first ANC visit } \\
\hline $4+$ months & 1602 & 15.5 & 74.5 & 69.6 & 33.2 \\
\hline$<4$ months & 8763 & 84.5 & 85.9 & 80.1 & 32.5 \\
\hline \multicolumn{6}{|l|}{ Quality of ANC } \\
\hline$\leq 5$ services & 1594 & 15.4 & 70.1 & 62.8 & 30.2 \\
\hline $6-7$ services & 4907 & 47.3 & 83.9 & 78.4 & 32.2 \\
\hline$>7$ services & 3865 & 37.3 & 90.2 & 84.9 & 33.8 \\
\hline \multicolumn{6}{|l|}{ Place of delivery } \\
\hline Not health facility & 2173 & 21.0 & 43.9 & 38.0 & \\
\hline Health facility & 8193 & 79.0 & 94.8 & 89.2 & \\
\hline \multicolumn{6}{|c|}{ Distance to health facility } \\
\hline Not a big problem & 9196 & 88.7 & 85.1 & 79.3 & 33.1 \\
\hline Big problem & 1169 & 11.3 & 76.2 & 71.7 & 28.3 \\
\hline \multicolumn{6}{|c|}{ Insured for health service } \\
\hline Uninsured & 4458 & 43.0 & 82.3 & 76.5 & 33.8 \\
\hline Insured & 5907 & 57.0 & 85.5 & 80.0 & 31.8 \\
\hline
\end{tabular}

(93.8\% and $94.8 \%$ respectively). Infants who were born in a health facility had the highest proportion of early first PNC (Table 1).

Controlling for infant's gender, birth ranking and interval, women's perception of infant size at birth, women's age, whether the pregnancy was wanted, age difference between woman and husband, husband's occupation and education, household wealth quintile, number of household member, number of children under five years old in the household, region, residence, number of ANC visits, ANC timing, ANC quality, place of delivery, distance to health facility, and ownership of health insurance, infants of women with high participation in the labor force had $32 \%$ greater odds of having any PNC compared to those with low labor force participation. An interaction was found between women's knowledge level and place of delivery ( $p$ for interaction $=0.0007$ ) for any PNC. Compared to those who were not born in a health facility, being born in a facility was associated with 22.11, 25.17 and 12.11 more odds of having any PNC for infants of women with low, medium and high knowledge level, respectively (Table 2).

Interactions between disagreement towards justification of wife beating and place of delivery ( $\mathrm{p}$ for interaction $=0.005)$, decision making power and infant's gender ( $\mathrm{p}$ for interaction $=0.004$ ) and knowledge level and place of delivery ( $\mathrm{p}$ for interaction $=0.002$ ) for early PNC were statistically significant. Compared to those not born in a health facility and adjusted for other covariates, being born in a 

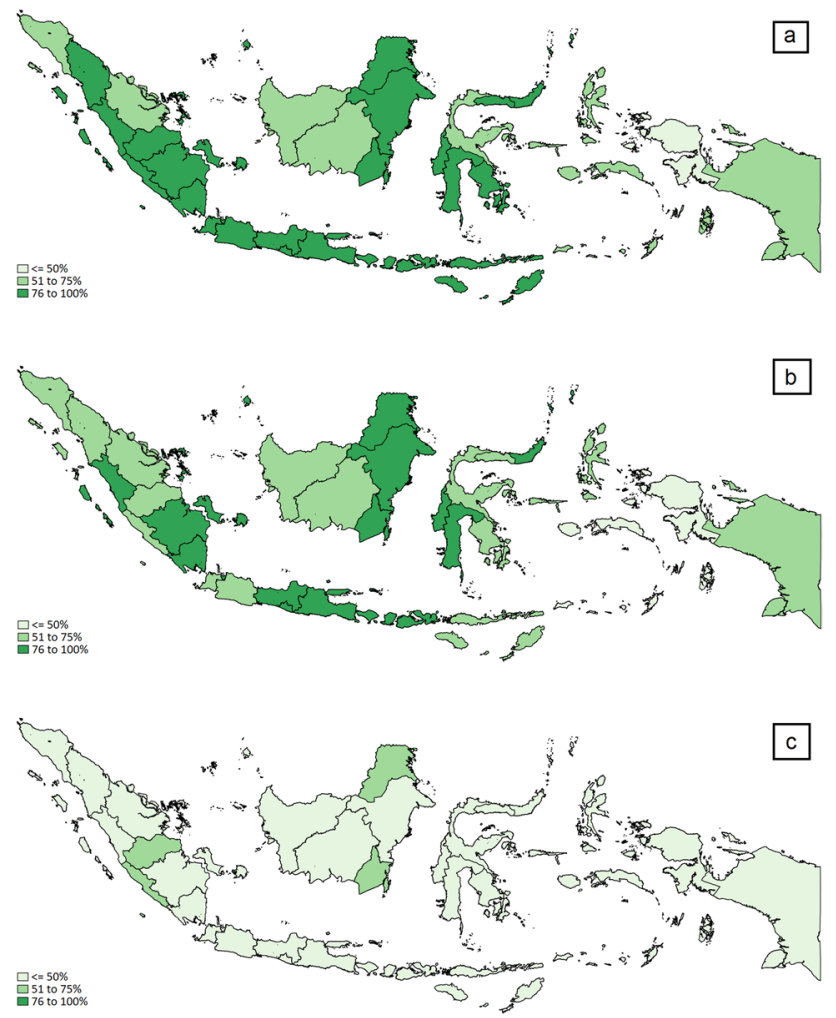

Fig. 1 Distribution of Prevalence of a Any Postnatal Care, b First Postnatal Care 2 days after birth and $\mathbf{c}$ Postnatal Care after discharge in Indonesia health facility was associated with 11.45, 20.04 and 16.75 more odds of having early PNC for infants of women with low, medium and high disagreement towards justification of wife beating, respectively. With the same comparison and adjustment, being born in a health facility was associated with $11.45,10.37$ and 6.14 more odds of having early PNC in infants of women with low, medium and high knowledge level. Meanwhile, male infants of women with high decision-making power had $27 \%$ lower odds of having early PNC compared to female infants (Table 2).

Infants of women with high disagreement towards justification of wife beating had $27 \%$ lower odds of having PNC after discharge. Compared to small infants, average and large infants of women with medium decision-making power had $51 \%$ and $48 \%$ greater odds of having PNC after discharge, respectively, and $36 \%$ and $39 \%$ lower odds of having PNC after discharge in women with high decision-making power (Table 2).

\section{Discussion}

\section{General Findings}

Utilization of PNC particularly in western Indonesia was already high, except for PNC after discharge, which was very low for those born in a health facility. However, utilization of PNC in eastern Indonesia was trailing behind in all indicators. Women's empowerment was associated with the use of PNC in Indonesia. Women's labor force

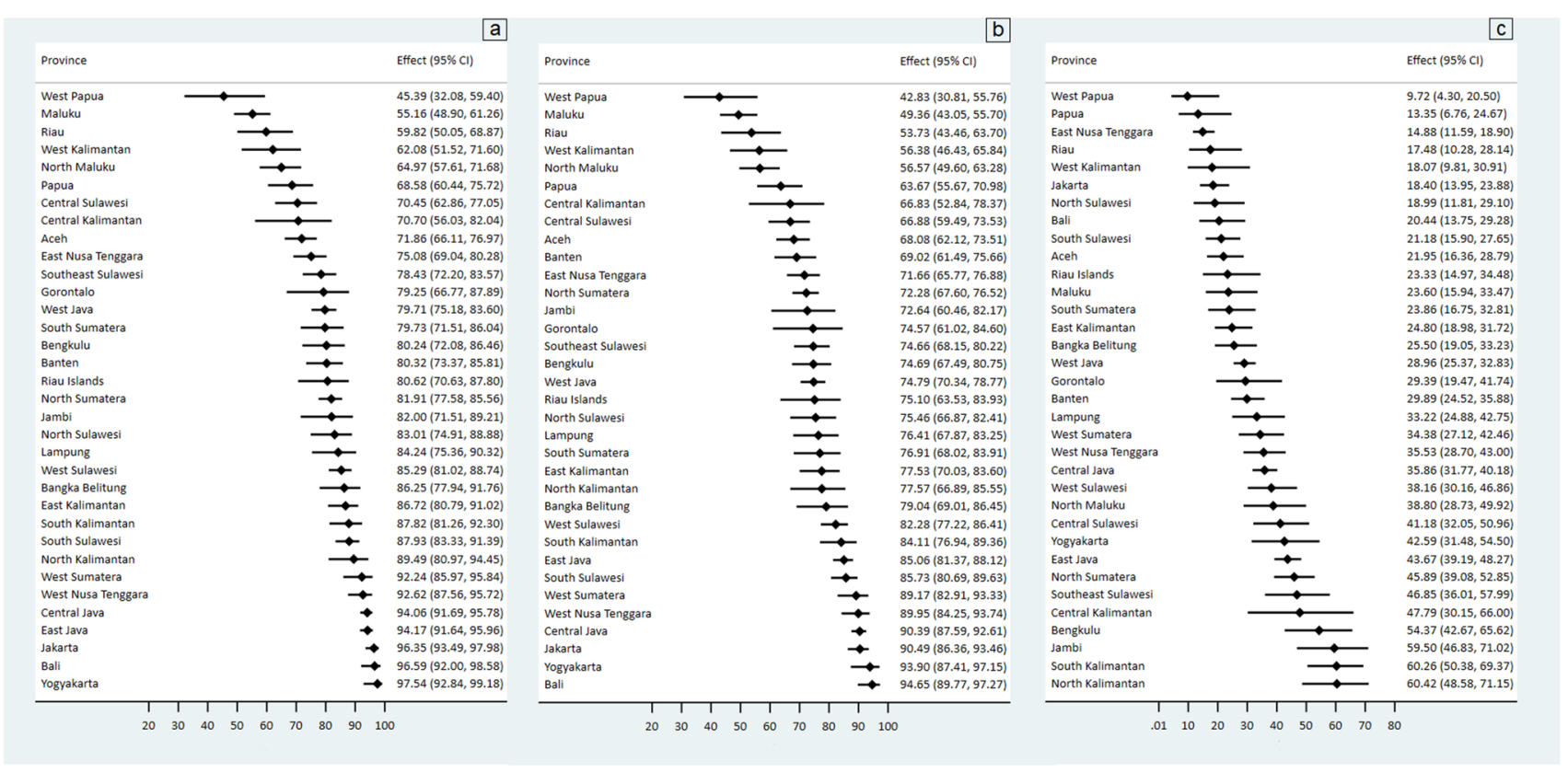

Fig. 2 Prevalence of a Any postnatal care, b First Postnatal Care within 2 days of birth and $\mathbf{c}$ Postnatal care after discharge by Province (Indonesian Demographic Health Survey 2017, population size $=10,365)$ 
Table 2 Association between women's empowerment indicators and receiving any postnatal care, postnatal care within two days of birth and postnatal care after discharge

\begin{tabular}{|c|c|c|c|c|c|c|}
\hline & \multicolumn{2}{|c|}{ Any postnatal care } & \multicolumn{2}{|c|}{ Postnatal care $<2$ days of delivery } & \multicolumn{2}{|c|}{$\begin{array}{l}\text { Postnatal care after dis- } \\
\text { charge }\end{array}$} \\
\hline & Adj odds ratio ${ }^{a}$ & $95 \%$ confidence interval & Adj odds ratio ${ }^{a}$ & $95 \%$ confidence interval & Adj odds ratio ${ }^{b}$ & $\begin{array}{l}95 \% \\
\text { confidence } \\
\text { interval }\end{array}$ \\
\hline \multicolumn{7}{|l|}{ Labor force participation } \\
\hline Low & Reference & & Reference & & Reference & \\
\hline Medium & 1.11 & $0.92-1.34$ & 0.96 & $0.81-1.13$ & 1.08 & $0.92-1.26$ \\
\hline High & $1.32 *$ & $1.06-1.64$ & 1.13 & $0.93-1.37$ & 1.10 & $0.93-1.30$ \\
\hline \multicolumn{7}{|l|}{$\begin{array}{l}\text { Disagreement towards } \\
\text { Justification of Wife } \\
\text { Beating }\end{array}$} \\
\hline Low & Reference & & & & Reference & \\
\hline Medium & 0.94 & $0.76-1.17$ & & & 0.95 & $0.79-1.14$ \\
\hline High & 0.91 & $0.74-1.12$ & & & $0.73 * * *$ & $0.63-0.86$ \\
\hline $\begin{array}{l}\text { Facility vs non-facility } \\
\text { birth in low disagree- } \\
\text { ment }\end{array}$ & & & $11.45^{* * *}$ & $8.11-16.18$ & & \\
\hline $\begin{array}{l}\text { Facility vs non-facility } \\
\text { birth in medium disa- } \\
\text { greement }\end{array}$ & & & $20.04 * * *$ & $14.77-27.19$ & & \\
\hline $\begin{array}{l}\text { Facility vs non-facility } \\
\text { birth in high disagree- } \\
\text { ment }\end{array}$ & & & $16.75^{* * *}$ & $11.65-24.09$ & & \\
\hline \multicolumn{7}{|l|}{ Decision making power } \\
\hline Low & Reference & & & & & \\
\hline Medium & 1.07 & $0.86-1.32$ & & & & \\
\hline High & 1.04 & $0.84-1.29$ & & & & \\
\hline $\begin{array}{l}\text { Male vs female infants in } \\
\text { low power }\end{array}$ & & & 1.08 & $0.86-1.36$ & & \\
\hline $\begin{array}{l}\text { Male vs female infants in } \\
\text { medium power }\end{array}$ & & & 1.22 & $0.97-1.55$ & & \\
\hline $\begin{array}{l}\text { Male vs female infants in } \\
\text { high power }\end{array}$ & & & $0.73 * *$ & $0.58-0.91$ & & \\
\hline $\begin{array}{l}\text { Average vs small infants } \\
\text { in low power }\end{array}$ & & & & & 1.21 & $0.87-1.67$ \\
\hline $\begin{array}{l}\text { Large vs small infants in } \\
\text { low power }\end{array}$ & & & & & 1.26 & $0.90-1.76$ \\
\hline $\begin{array}{l}\text { Average vs small infants } \\
\text { in medium power }\end{array}$ & & & & & $1.51^{*}$ & $1.06-2.15$ \\
\hline $\begin{array}{l}\text { Large vs small infants in } \\
\text { medium power }\end{array}$ & & & & & $1.48^{*}$ & $1.02-2.14$ \\
\hline $\begin{array}{l}\text { Average vs small infants } \\
\text { in high power }\end{array}$ & & & & & $0.64 * *$ & $0.46-0.89$ \\
\hline $\begin{array}{l}\text { Large vs small infants in } \\
\text { high power }\end{array}$ & & & & & $0.61 * *$ & $0.43-0.86$ \\
\hline \multicolumn{7}{|l|}{ Women's knowledge level } \\
\hline Low & & & & & Reference & \\
\hline Medium & & & & & 0.95 & $0.80-1.13$ \\
\hline High & & & & & 1.07 & $0.89-1.28$ \\
\hline $\begin{array}{l}\text { Facility vs non-facility } \\
\text { birth in low knowledge } \\
\text { level }\end{array}$ & $22.11 * * *$ & $16.16-30.25$ & $11.45^{* * *}$ & $8.11-16.18$ & & \\
\hline
\end{tabular}


Table 2 (continued)

\begin{tabular}{|c|c|c|c|c|c|c|}
\hline & \multicolumn{2}{|c|}{ Any postnatal care } & \multicolumn{2}{|c|}{ Postnatal care $<2$ days of delivery } & \multicolumn{2}{|c|}{$\begin{array}{l}\text { Postnatal care after dis- } \\
\text { charge }\end{array}$} \\
\hline & Adj odds ratio ${ }^{\mathrm{a}}$ & $95 \%$ confidence interval & Adj odds ratio ${ }^{\mathrm{a}}$ & $95 \%$ confidence interval & Adj odds ratio ${ }^{b}$ & $\begin{array}{l}95 \% \\
\text { confidence } \\
\text { interval }\end{array}$ \\
\hline $\begin{array}{l}\text { Facility vs non-facility } \\
\text { birth in medium knowl- } \\
\text { edge level }\end{array}$ & $25.17 * * *$ & $18.42-34.38$ & $10.37 * * *$ & $7.61-14.14$ & & \\
\hline $\begin{array}{l}\text { Facility vs non-facility } \\
\text { birth in high knowledge } \\
\text { level }\end{array}$ & $12.11 * * *$ & $8.95-16.37$ & $6.14 * * *$ & $4.48-8.41$ & & \\
\hline \multicolumn{7}{|c|}{$* * * \mathrm{p}<0.001, * * \mathrm{p}<0.01, * \mathrm{p}<0.05$} \\
\hline \multicolumn{7}{|c|}{$\begin{array}{l}\text { 'Adjusted for child's gender, birth ranking and interval, women's perception of child size at birth, women's age, whether the pregnancy was } \\
\text { wanted, age difference between women and husband, husband's occupation, husband's education, wealth quintile, number of household member, } \\
\text { number of children under } 5 \text { in household, region, residence, number of antenatal care (ANC) visits, ANC timing, quality of ANC, place of deliv- } \\
\text { ery, distance to health facility, ownership of health insurance }\end{array}$} \\
\hline \multicolumn{7}{|c|}{$\begin{array}{l}\text { 'Adjusted for child's gender, birth ranking and interval, women's perception of child size at birth, women's age, whether the pregnancy was } \\
\text { wanted, age difference between women and husband, husband's occupation, husband's education, wealth quintile, number of household member, } \\
\text { number of children under } 5 \text { in household, region, residence, number of antenatal care (ANC) visits, ANC timing, quality of ANC, distance to } \\
\text { health facility, ownership of health insurance }\end{array}$} \\
\hline
\end{tabular}

participation was positively associated with any PNC. Disagreement towards justification of wife beating was negatively associated with PNC after discharge. The difference in the odds of having early PNC between infants who were born in a facility and not was the greatest in women who had medium level of disagreement towards justification of wife beating. Male infants had lower odds of having early PNC compared to female infants when their mother had high decision-making power. Average and large infants had higher odds of having PNC after discharge compared to small infants when their mother had a medium level decision-making power; but average and large infants had lower odds of having PNC after discharge compared to small infants when their mother had high decision-making power. Infants who were born in a health facility had a greater odds of having any PNC, and early PNC compared to those not born in a health facility, but the difference in the odds were smallest when their mother had high knowledge level.

\section{Comparison with Other Studies}

The positive association between labor force participation and PNC is similar to a study from Bangladesh (Ahmmed, 2021) but not in line with the lack of association between labor force participation and antenatal care in Indonesia (Sebayang et al., 2019). The negative association between disagreement towards justification of wife beating and PNC after discharge is not in line with a study from Bangladesh that reported PNC was higher in women who disagreed with wife beating (Ahmmed, 2021).
Positive association between decision-making power and having any PNC and early first PNC has been reported in Myanmar, where male involvement was associated with utilizing PNC (Mon et al., 2018). In Ethiopia, women who are able to make decisions have nearly twice the odds of having PNC for newborns (Chaka et al., 2019). In our study, however, this association was modified by child's gender and size for early PNC and PNC after discharge. The association between women's knowledge level and any PNC has been reported in Ethiopia (Angore et al., 2018; Sisay et al., 2019), Nigeria (Agho et al., 2016; Somefun \& Ibisomi, 2016), Zambia (Bwalya et al., 2017), Sudan (Izudi et al., 2017), Pakistan (Sultana \& Shaikh, 2015), Myanmar (Mon et al., 2018), Malawi(Machira \& Palamulen, 2017), and other low middle income countries (Langlois et al., 2015) where women with a lower education level had lower odds of attending PNC. Our finding shows that place of delivery is an important effect modifier for this association.

\section{Possible Mechanism}

The low PNC after discharge was possibly due to prevailing belief in the Indonesian community to not take newborns out of the house before 40 days of birth (Busro \& Qodim, 2018; Dewi, 2020). A previous study reported no association between women's labor force participation and the use of antenatal care in Indonesia (Sebayang et al., 2019) possibly due to the free antenatal care service at village level provided by village midwives. It is interesting that we found a positive association for any $\mathrm{PNC}$, despite available free PNC service, even after adjustment to household wealth. 
This indicates a different mechanism in the decision to utilize PNC compared to ANC. Women with high participation in the labor force may have income to pay for extra costs for better PNC service or they may have support and suggestions from female work colleagues who have experience with newborn care and PNC service.

Women with high disagreement with justification of wife beating may be those who are confident about the health and survival of their infants or perceive that their newborns are healthy and thus do not need any PNC immediately. Similarly, women with high decision-making power may be over-confident in their newborn's health when they give birth to male and average or large infants and thus decide not to bring them for PNC early or after discharge. This indicates that women's confidence about the infant's health may be key. In Myanmar and Ethiopia, women's awareness of postnatal danger signs is associated with improved PNC usage (Mon et al., 2018). A study in China, for example, reported that $24 \%$ of women thought that PNC was unnecessary (Chen et al., 2014). Similarly, a study in Indonesia reported that PNC was perceived to be necessary only when obstetric complications occurred (Titaley et al., 2010). It is not surprising that in Bangladesh newborns whose mothers reported complications had higher odds of receiving PNC (Singh et al., 2017). A study in Indonesia reported that the power play between women and their extended families influenced and might hinder the decision to seek PNC (Probandari et al., 2017). However, our studies show that involvement of family or community members who are more experienced with correct infant care in PNC decision making may be key.

Our study shows that women's knowledge level is an important factor in PNC utilization. Women with high knowledge level might be more able to understand the importance of PNC thus women with high knowledge would still bring their newborns for early PNC even when they did not give birth in a health facility.

\section{Strength and Weakness}

This is the first study in Indonesia that assesses specifically the association between women's empowerment and the use of PNC. We adjusted the analysis for covariates including socioeconomic status and quality of health care. This study used nationally representative data, however due to the cross-sectional design we cannot infer a causal relation.

\section{Policy Implication and Further Study}

Although the prevalence of having at least one PNC visit during the neonatal period in Indonesia is already high, the low usage of PNC early after birth especially in eastern
Indonesia, and PNC after discharge for those born in a health facility, calls for an immediate program to improve PNC for newborns. The Indonesian government should consider a nationwide PNC promotional program to inform women of the need for PNC early and after discharge, regardless of the place they give birth. This program is crucially needed also because many community-based maternal and child health care services have been postponed during the Covid-19 pandemic to avoid crowding. The promotional program should be coupled with an education program to inform women of the importance of PNC for their newborns even if their newborns look healthy.

Even in a developed country, women need more information regarding available PNC service (McLeish et al., 2020). In Argentina, $>90 \%$ of women were willing to receive an SMS on health information after giving birth, more than $80 \%$ wanted appointment reminders, $90 \%$ wanted information on lactation and on when to call a doctor (Cormick et al., 2012). This suggests that education on the importance of PNC can be delivered not only by conventional methods such as the use of a maternal and child health handbook (Kaneko et al., 2017), but also through SMS and internet communication. mHealth interventions have been shown to be effective in promoting the use of PNC (Feroz et al., 2017; Watterson et al., 2015). A locally customized mHealth application can significantly improve the utilisation of PNC services, possibly through positively influencing the health seeking behaviour of health workers and their clients (Shiferaw et al., 2016). It can be used particularly to provide postnatal health information and to remind women to access PNC after discharge.

Other creative programs such as monetary incentives for patients, providers or community health cadres for referring to PNC and strengthening women's group (Kearns et al., 2016) and birth plans programs during ANC services (Magoma et al., 2013) could be adapted to the maternal and child health care system in Indonesia to increase the use of PNC.

Policies to improve women's labor force participation in Indonesia are also needed. The recommended policies include creating job opportunities for women, providing financial supports for female entrepreneurs such as microfinance and incentives, and providing other supports to keep women in the work force after giving birth. A study reported that microfinance provided for groups, for example, improves utilization of health care (Orton et al., 2016). A study to learn the impact of such intervention in Indonesia is necessary. The pathway between women's labor force participation and PNC utilization may be through the availability of groups of people from the workplace who provide support and become role models for good PNC seeking. This pathway also needs further research investigation. 


\section{Conclusions for Practice}

The prevalence of any PNC by skilled professionals in Indonesia was high but PNC coverage after discharge was very low. Utilization of PNC in eastern Indonesia was trailing behind in all indicators. Women's empowerment was associated with the use of PNC but the association varied with place of delivery, child's gender or size. Women's empowerment indicators, particularly labor force participation, decision-making power and women's knowledge level, need to be addressed in maternal and child health programs.

Supplementary Information The online version contains supplementary material available at https://doi.org/10.1007/s10995-021-03324-y.

Acknowledgements We would like to thank Universitas Airlangga, Indonesia for supporting this study through Hibah Riset Mandat Grant.

Author Contributions SKS: Conceptualization; data curation; formal analysis; methodology; visualization; roles/writing—original draft. EMMH, SH: Writing-review \& editing. FE: Conceptualization, writing-review \& editing. EA: Formal analysis, writing-review \& editing. HK: Writing—review \& editing.

Funding This study was funded by Universitas Airlangga, Surabaya, Indonesia through "Hibah Riset Mandat" Scheme (Grant No. 335/ UN3.14/LT/2019).

Data Availability Datasets are available at www.dhsprogram.com.

Code Availability Not applicable.

\section{Declarations}

Conflict of interest The authors declare no conflicts of interest.

Ethical Approval A de-identified dataset made available by ICF at www.dhsprogram.com was used for analysis. The institutionalized Review Board (IRB) in ICF, as the DHS survey implementing agency, and the IRB in host countries approved the survey protocols. No further consent was needed for this analysis.

Consent to Participate Not applicable.

Consent for Publication Not applicable.

\section{References}

AbukaAbebo, T., \& JemberTesfaye, D. (2018). Postnatal care utilization and associated factors among women of reproductive age Group in Halaba Kulito Town, Southern Ethiopia. Archives of Public Health, 76, 9. https://doi.org/10.1186/s13690-018-0256-6

Agho, K. E., Ezeh, O. K., Issaka, A. I., Enoma, A. I., Baines, S., \& Renzaho, A. M. (2016). Population attributable risk estimates for factors associated with non-use of postnatal care services among women in Nigeria. British Medical Journal Open, 6(7), e010493. https://doi.org/10.1136/bmjopen-2015-010493
Ahmmed, F. (2021). Women's empowerment and practice of maternal healthcare facilities in Bangladesh: A trend analysis. Journal of Health Research. https://doi.org/10.1108/JHR-11-2020-0559

Angore, B. N., Tufa, E. G., \& Bisetegen, F. S. (2018). Determinants of postnatal care utilization in urban community among women in Debre Birhan Town, Northern Shewa, Ethiopia. Journal of Health, Population \& Nutrition, 37(1), 10. https://doi.org/10. 1186/s41043-018-0140-6

Baqui, A. H., Ahmed, S., El Arifeen, S., Darmstadt, G. L., Rosecrans, A. M., Mannan, I., Rahman, S. M., Begum, N., Mahmud, A. B. A., Seraji, H. R., Williams, E. K., Winch, P. J., Santosham, M., Black, R. E., for the Projahnmo 1 Study Group. (2009). Effect of timing of first postnatal care home visit on neonatal mortality in Bangladesh: A observational cohort study. BMJ, 339, b2826. https://doi.org/10.1136/bmj.b2826

Blencowe, H., Cousens, S., Mullany, L. C., Lee, A. C., Kerber, K., Wall, S., Darmstadt, G. L., \& Lawn, J. E. (2011). Clean birth and postnatal care practices to reduce neonatal deaths from sepsis and tetanus: A systematic review and Delphi estimation of mortality effect. BMC Public Health, 11(Suppl 3), S11. https://doi.org/10. 1186/1471-2458-11-S3-S11

Busro, B., \& Qodim, H. (2018). Perubahan Budaya dalam Ritual Slametan Kelahiran di Cirebon, Indonesia. Jurnal Studi Agama Dan Masyarakat, 14(2), 127-147.

Bwalya, B. B., Mulenga, M. C., \& Mulenga, J. N. (2017). Factors associated with postnatal care for newborns in Zambia: Analysis of the 2013-14 Zambia demographic and health survey. BMC Pregnancy \& Childbirth, 17(1), 418. https://doi.org/10.1186/ s12884-017-1612-1

Chaka, E. E., Abdurahman, A. A., Nedjat, S., \& Majdzadeh, R. (2019). Utilization and Determinants of postnatal care services in Ethiopia: A systematic review and meta-analysis. Ethiopian Journal of Health Sciences, 29(1), 935-944. https://doi.org/10.4314/ejhs. v29i1.16

Chen, L., Qiong, W., van Velthoven, M. H., Yanfeng, Z., Shuyi, Z., Ye, L., Wei, W., Xiaozhen, D., \& Ting, Z. (2014). Coverage, quality of and barriers to postnatal care in rural Hebei, China: A mixed method study. BMC Pregnancy \& Childbirth, 14, 31. https://doi. org/10.1186/1471-2393-14-31

Cormick, G., Kim, N. A., Rodgers, A., Gibbons, L., Buekens, P. M., Belizan, J. M., \& Althabe, F. (2012). Interest of pregnant women in the use of SMS (short message service) text messages for the improvement of perinatal and postnatal care. Reproductive Health, 9,9.

Dewi, R. (2020). Tradisi Marapi dan Hubungannya Dengan Kesehatan Ibu dan Bayi (Studi Fenomenologi di Desa Manunggang Jae). (Master Degree), Universitas Sumatera Utara, Medan

Fadel, S. A., Ram, U., Morris, S. K., Begum, R., Shet, A., Jotkar, R., \& Jha, P. (2015). Facility delivery, postnatal care and neonatal deaths in India: Nationally-representative case-control studies. PLoS ONE, 10(10), e0140448. https://doi.org/10.1371/journal. pone. 0140448

Fekadu, G. A., Kassa, G. M., Berhe, A. K., Muche, A. A., \& Katiso, N. A. (2018). The effect of antenatal care on use of institutional delivery service and postnatal care in Ethiopia: A systematic review and meta-analysis. BMC Health Services Research, 18(1), 577. https://doi.org/10.1186/s12913-018-3370-9

Feroz, A., Perveen, S., \& Aftab, W. (2017). Role of mHealth applications for improving antenatal and postnatal care in low and middle income countries: A systematic review. BMC Health Services Research, 17(1), 704. https://doi.org/10.1186/s12913-017-2664-7

Izudi, J., Akwang, G. D., \& Amongin, D. (2017). Early postnatal care use by postpartum mothers in Mundri East County South Sudan. BMC Health Services Research, 17(1), 442. https://doi.org/10. 1186/s12913-017-2402-1 
Kaneko, K., Niyonkuru, J., Juma, N., Mbonabuca, T., Osaki, K., \& Aoyama, A. (2017). Effectiveness of the maternal and child health handbook in Burundi for increasing notification of birth at health facilities and postnatal care uptake. Global Health Action, 10(1), 1297604. https://doi.org/10.1080/16549716.2017.1297604

Kearns, A. D., Caglia, J. M., Ten Hoope-Bender, P., \& Langer, A. (2016). Antenatal and postnatal care: A review of innovative models for improving availability, accessibility, acceptability and quality of services in low-resource settings. BJOG: an International Journal of Obstetrics \& Gynaecology, 123(4), 540-548. https://doi.org/10. 1111/1471-0528.13818

Khan, S. M., Speizer, I. S., Singh, K., Angeles, G., Twum-Danso, N. A., \& Barker, P. (2017). Does postnatal care have a role in improving newborn feeding? A study in 15 sub-Saharan African countries. Journal of Global Health, 7(2), 020506. https://doi.org/10.7189/ jogh.07.020506

Khanal, V., Adhikari, M., Karkee, R., \& Gavidia, T. (2014). Factors associated with the utilisation of postnatal care services among the mothers of Nepal: Analysis of Nepal demographic and health survey 2011. BMC Women's Health, 14, 19. https://doi.org/10.1186/ 1472-6874-14-19

Kikuchi, K., Yasuoka, J., Nanishi, K., Ahmed, A., Nohara, Y., Nishikitani, M., Yokota, F., Mizutani, T., \& Nakashima, N. (2018). Postnatal care could be the key to improving the continuum of care in maternal and child health in Ratanakiri, Cambodia. PLOS ONE, 13(6), e0198829. https://doi.org/10.1371/journal.pone.0198829

Langlois, E. V., Miszkurka, M., Zunzunegui, M. V., Ghaffar, A., Ziegler, D., \& Karp, I. (2015). Inequities in postnatal care in low- and middle-income countries: A systematic review and meta-analysis. Bulletin of the World Health Organization, 93(4), 259-270G. https:// doi.org/10.2471/BLT.14.140996

Machira, K., \& Palamulen, M. (2017). Rural-urban differences in the use of postnatal care services in Malawi. Journal of the Egyptian Public Health Association, 92(1), 1-10. https://doi.org/10.21608/ epx.2017.7003

Magoma, M., Requejo, J., Campbell, O., Cousens, S., Merialdi, M., \& Filippi, V. (2013). The effectiveness of birth plans in increasing use of skilled care at delivery and postnatal care in rural Tanzania: A cluster randomised trial. Tropical Medicine \& International Health, 18(4), 435-443. https://doi.org/10.1111/tmi.12069

McLeish, J., Harvey, M., Redshaw, M., \& Alderdice, F. (2020). "Reassurance that you're doing okay, or guidance if you're not": A qualitative descriptive study of pregnant first time mothers' expectations and information needs about postnatal care in England. Midwifery, 89, 102813.

Mon, A. S., Phyu, M. K., Thinkhamrop, W., \& Thinkhamrop, B. (2018). Utilization of full postnatal care services among rural Myanmar women and its determinants: A cross-sectional study. F1000Research, 7, 1167. https://doi.org/10.12688/f1000research.15561.1

Okawa, S., Ansah, E. K., Nanishi, K., Enuameh, Y., Shibanuma, A., Kikuchi, K., Yasuoka, J., Gyapong, M., Owusu-Agyei, S., Rexford Oduro, A., QuansahAsare, G., Hodgson, A., Jimba, M., Ghana EMBRACE Implementation Research Project Team. (2015). High incidence of neonatal danger signs and its implications for postnatal care in Ghana: A cross-sectional study. PLoS ONE, 10(6), e0130712. https://doi.org/10.1371/journal.pone.0130712

Orton, L., Pennington, A., Nayak, S., Sowden, A., White, M., \& Whitehead, M. (2016). Group-based microfinance for collective empowerment: A systematic review of health impacts. Bulletin of the World Health Organization, 94(9), 694-704A.

Probandari, A., Arcita, A., Kothijah, K., \& Pamungkasari, E. P. (2017). Barriers to utilization of postnatal care at village level in Klaten district, central Java Province, Indonesia. BMC Health Services Research, 17(1), 541. https://doi.org/10.1186/s12913-017-2490-y

Sacks, E., \& Langlois, E. V. (2016). Postnatal care: Increasing coverage, equity, and quality. The Lancet Global Health, 4(7), e442-443. https://doi.org/10.1016/S2214-109X(16)30092-4
Sakeah, E., Aborigo, R., Sakeah, J. K., Dalaba, M., Kanyomse, E., Azongo, D., Anaseba, D., Oladokun, S., \& Oduro, A. R. (2018). The role of community-based health services in influencing postnatal care visits in the Builsa and the West Mamprusi districts in rural Ghana. BMC Pregnancy \& Childbirth, 18(1), 295. https://doi.org/ 10.1186/s12884-018-1926-7

Sebayang, S. K., Efendi, F., \& Astutik, E. (2019). Women's empowerment and the use of antenatal care services: Analysis of demographic health surveys in five Southeast Asian countries. Women \& Health. https://doi.org/10.1080/03630242.2019.1593282

Shiferaw, S., Spigt, M., Tekie, M., Abdullah, M., Fantahun, M., \& Dinant, G. J. (2016). The effects of a locally developed mHealth intervention on delivery and postnatal care utilization; a prospective controlled evaluation among health centres in Ethiopia. PLOS ONE, 11(7), e0158600. https://doi.org/10.1371/journal.pone.0158600

Singh, A., Padmadas, S. S., Mishra, U. S., Pallikadavath, S., Johnson, F. A., \& Matthews, Z. (2012). Socio-economic inequalities in the use of postnatal care in India. PLoS ONE, 7(5), e37037. https://doi.org/ 10.1371/journal.pone.0037037

Singh, K., Brodish, P., \& Haney, E. (2014). Postnatal care by provider type and neonatal death in sub-Saharan Africa: A multilevel analysis. BMC Public Health, 14, 941. https://doi.org/10.1186/ 1471-2458-14-941

Singh, K., Brodish, P., Chowdhury, M. E., Biswas, T. K., Kim, E. T., Godwin, C., \& Moran, A. (2017). Postnatal care for newborns in Bangladesh: The importance of health-related factors and location. Journal of Global Health, 7(2), 020507. https://doi.org/10.7189/ jogh.07.020507

Sisay, M. M., Geremew, T. T., Demlie, Y. W., Alem, A. T., Beyene, D. K., Melak, M. F., Gelaye, K. A., Ayele, T. A., \& Andargie, A. A. (2019). Spatial patterns and determinants of postnatal care use in Ethiopia: Findings from the 2016 demographic and health survey. British Medical Journal Open, 9(6), e025066. https://doi.org/10. 1136/bmjopen-2018-025066

Somefun, O. D., \& Ibisomi, L. (2016). Determinants of postnatal care non-utilization among women in Nigeria. BMC Research Notes, 9 , 21. https://doi.org/10.1186/s13104-015-1823-3

Statistics Indonesia (Badan Pusat Statistik-BPS), National Population and Family Planning Board (BKKBN), and Kementerian Keseha$\tan$ (Kemenkes-MOH), and ICF International. (2013). Indonesia Demographic and Health Survey 2012. Jakarta, Indonesia: BPS, BKKBN, Kemenkes, and ICF International

Sultana, N., \& Shaikh, B. T. (2015). Low utilization of postnatal care: Searching the window of opportunity to save mothers and newborns lives in Islamabad capital territory, Pakistan. BMC Research Notes, 8, 645. https://doi.org/10.1186/s13104-015-1646-2

Titaley, C. R., Dibley, M. J., Agho, K., Roberts, C. L., \& Hall, J. (2008). Determinants of neonatal mortality in Indonesia. BMC Public Health, 8, 232. https://doi.org/10.1186/1471-2458-8-232

Titaley, C. R., Hunter, C. L., Heywood, P., \& Dibley, M. J. (2010). Why don't some women attend antenatal and postnatal care services?: A qualitative study of community members' perspectives in Garut, Sukabumi and Ciamis districts of West Java Province, Indonesia. BMC Pregnancy \& Childbirth, 10, 61. https://doi.org/10.1186/ 1471-2393-10-61

Watterson, J. L., Walsh, J., \& Madeka, I. (2015). Using mHealth to improve usage of antenatal care, postnatal care, and immunization: A systematic review of the literature. BioMed Research International, 2015, 153402. https://doi.org/10.1155/2015/153402

Publisher's Note Springer Nature remains neutral with regard to jurisdictional claims in published maps and institutional affiliations. 